International Journal of Linguistics, Literature and Translation

ISSN: 2617-0299 (Online); ISSN: 2708-0099 (Print)

DOI: $10.32996 / \mathrm{ijllt}$

Journal Homepage: www.al-kindipublisher.com/index.php/ijltt

IJLLT

\title{
Interactional Patterns in English as a Second Language Classrooms at Higher Learning
}

\author{
Dr. Golebamang Galegane \\ Lecturer, Communication and Study Skills Unit, University of Botswana, Gaborone, Botswana
}

$\square$ Corresponding Author: Dr Golebamang Galegane, E-mail: galegane@UB.AC.BW

\section{ARTICLE INFORMATION}

Received: 08 October 2021

Accepted: 14 November 2021

Published: 30 November 2021

DOI: $10.32996 /$ ijltt.2021.4.11.1

\section{KEYWORDS}

Interactional Patterns, Initiation, Response, Feedback, Sociocultural Theory, Classroom Discourse

\section{ABSTRACT}

This study investigates the interactional patterns that were used in ESL classrooms at higher learning at the University of Botswana and the reasons for the said patterns. A qualitative approach was employed and the classroom observations were used to investigate the topic. To further shed some light on the patterns used in the CSS classrooms, reference will be made to Vygotsky's sociocultural theory and Sinclair \& Coulthard's Initiation, Response, Feedback (IRF) analytical tool. The results indicated that there were 'new' interactional patterns at the University of Botswana classrooms. Some of these were Initiation Response (IR) and Initiation Response Response (IRR) which led to the conclusions that the patterns of interaction which emanated from the study were, "better", "good", and "not so good" (BGN interactional patterns). This study concludes that there is an attempt to produce quality classroom interaction as the interactional patterns of "better", "good", and "not so good" (BGN interactional patterns) were demonstrated with the first two categories carrying higher percentages.

\section{Introduction}

Interactional patterns in higher learning are very important because they act as a springboard to the students' success (Thoms, 2012; Lefstein \& Snell, 2014). The contributing factor to the aforementioned could be that if the students and the lecturers interact very well, there would be quality classroom talk. This is because the students would think of what to say in class and then freely share their thoughts with the rest of the class.

The discourse used during classroom interaction has been described to be very useful (Maftoon \& Ziafar, 2013) because it helps to draw conclusions regarding both the students' and the lecturers' talk. The classroom discourse further helps the students to convey their ideas, hence, demonstrating better interactional patterns. From the lecturers' perspective, classroom discourse helps them to be mindful of the questions that they pose to the students. This is because open questions would contribute to more student talk which would lead to what (Goodwin, 2012; Price, 2017 \& Rustandi, 2017) termed an "articulate classroom". This research paper will describe and analyze the interactional patterns that were reflected between the students and lecturers in Communication and Study Skills (CSS) classes of the University of Botswana.

Generally, studies of classroom interaction (e.g. Xie, 2008; Rajab, 2012) have debated the traditional teacher-controlled teaching and learning. In this study, however, the interactional patterns at higher learning were investigated and the current trend established. This study, therefore, sought to establish the interaction patterns in the classroom whether they would be skewed towards the lecturers, the students or there would be a balance between the two. In finding answers to the above research problem, only two research questions will be addressed: i) What pattern(s) of classroom interaction emanates from the CSS classrooms? ii) Why are such patterns found in ESL classrooms in higher learning?

\section{Literature Review}

The past three decades have seen a rapid increase in the study of interactional patterns in various classroom contexts. In defining the term, interactional patterns are the way in which the lecturer and the students are actively commenting, building, and reasoning together during the teaching-learning process (Hennessy., Warwick., \& Mercer. (2011). According to Brown (2007), interaction is when the lecturers and the students put ideas together, resulting in a certain outcome.

Copyright: (C) 2021 the Author(s). This article is an open access article distributed under the terms and conditions of the Creative Commons Attribution (CC-BY) 4.0 license (https://creativecommons.org/licenses/by/4.0/). Published by Al-Kindi Centre for Research and Development, London, United Kingdom. 
One major issue relating to the purpose of interactional patterns is that they are meant to show what is being learned in the classroom and how it is being learned (Sundari., Rafli \& Ridwan, 2017). This observation, in a way, relates to this study's research questions as the kind of patterns used in CSS will be investigated together with the reasons that lead to such patterns.

In addition, the foregoing patterns can be categorized under classroom communication which according to Seedhouse (1996), is a sociolinguistic variety or institutional discourse type. Thus, interactional patterns reflect the way the lecturer and the students engage in classroom talk. From a related perspective, (Zakime, 2019; Aranda, et al., 2020) observed interactional patterns as the different possibilities in which students can interact with each other and with the teacher in the classroom. The said interaction has been termed by Zhan., Wu., Lin., \& Cai (2021) as "student-driven teacher talk". The findings from the above scholars suggest that classroom discourse, between the lecturers and the students, comes in "different pedagogical packages".

Seliger (1977) studied the interaction patterns and the findings revealed that these can be categorized into two namely, high input and low input generators. The scholar further found out that the above two patterns are determined by how interaction takes place in the classroom. From another related point of view, Phillips \& Bond, (2004) reviewed critical thinking and pointed out that it is when one views something from different angles. Thus, categorizing interactional patterns can be critically thought of by employing both the high input and the low input generators. Studying the pattern of interaction in the classroom is important as it involves critical thinking.

On the other hand, Wanatabe \& Swain (2007) found out that there are collaborative patterns of interaction. The two scholars explained that classroom interaction improves when the students work together with their lecturer for the improvement of interaction. Meanwhile, Sari (2018) discovered, in her study, that there were a number of interactional patterns in the EFL classrooms that were observed. Some of these patterns of interaction were choral responses, closed-ended teacher questioning (IRF), individual work, student initiates-teacher answers, open-ended teacher questioning, and collaboration. It is interesting to point out that both Wanatabe \& Swain agree (2007) with Sari (2018) on collaborative patterns of classroom interaction. The foregoing patterns were defined as a combined academic effort between the students and the lecturer.

Researchers such as Panova \& Lyster (2002) studied the patterns in classroom interaction focusing on the pattern illustrated by the Feedback Move. The above scholars' study mainly concentrated on adult learners and their findings revealed that the recasts and translations are the patterns relating to the Feedback Move.

\subsection{The Theoretical Framework}

This study is framed around Vygotsky's (1978) sociocultural theory (SCT) in which scaffolding, co-construction of knowledge and mediation, are the key components and they tend to reflect the classroom interaction during the teaching and learning process. The key factors to be considered in benchmarking the findings of this study are described as follows; scaffolding is the instructional structure whereby the teacher models the desired learning strategy or task then gradually shifts responsibility to the students (Turuk, 2008). Some studies have found out that co-construction of knowledge "is the process of producing a meaningful utterance for others, the speaker has to formulate a suitable response contingent on what others have said and the particular goals and nature of the activity, and which also augments the shared understanding attained thus far" (Cross, 2010, p. 283). Consequently, lecturers have to guide the students during classroom talk, and the students would, in turn, provide feedback to the lecturer and the entire class. It is from the previously mentioned dialogue, that the interactional patterns would unfold. Finally, in mediation, symbolic tools are used to regulate the relationships between the lecturer and the students, thus aiming to change the nature of these relationships by determining the interactional patterns (Lantolf, 2000). Some studies have attempted to further explain mediation and stated that it involves people who enhance their learning by selecting and shaping the learning experiences presented to them (Turuk, 2008). A relationship exists between all the above scholars in a number of ways; one is that the language used by the students in the classroom(s), helps students to think critically before providing answers, which in turn describe the interactional patterns. The second point relates to how the scholars view the three tenets of the SCT discussed above. From the aforementioned scholars' general observations, the lecturer will present the topic of the day (scaffolding) and as the dialogue unfolds in the classroom (co-construction of knowledge), it augments the language used by making the students think critically (mediation).

One of the advantages of the SCT is that it helps the lecturers and the students to understand how people learn in social contexts (learn from each other) and informs us on how lecturers construct active learning communities. This suggests that the teaching and learning that takes place in the classroom helps one to talk in a certain manner. The above point relates to the literature as Seedhouse (1996) pointed out that classroom interaction is a sociolinguistic aspect.

Vygotsky argued, 'that language is the main tool that promotes thinking, develops reasoning, and supports cultural activities like reading and writing' (Vygotsky, 1978). This suggests that, for the interaction patterns to come up during the teaching and learning process, a language should be used and in this study, the said language would be English. 
The SCT has been chosen in framing this study because it acts as a "mirror" during the interactional patterns in the classroom. The students' and the lecturers' interactional patterns are observed, herein, based on how the two parties exchange the classroom talk.

\subsection{The Framework: IRF Analytical tool}

The IRF analytical tool was used in this study because it shows the process in which the lecturers talk with their students, hence, showing the interactional patterns that are revealed during the pedagogical processes in ESL classrooms (Bunyi, 2005; Rustandi, 2017; $\mathrm{Li}$, 2018). Therefore, the IRF uncovers the different ways in which the lecturers interact with their students.

The interactional patterns studied in this paper are grounded on Sinclair \& Coulthard's (1975) analytical tool of the Initiation, Response, and Feedback (IRF). The IRF has been defined by (Wells, 1993) as a particular variant of exchange structure in which the teacher, by virtue of his or her status as primary actor or knower, both initiates the exchange and provides evaluation or follow-up to the student's medial responding move. Thus, the IRF develops when the lecturer presents the topic understudy to the students who in turn make some contributions before the teacher can evaluate the students' responses. In a conclusive manner, Seedhouse (1996) maintained that Sinclair \& Coulthard (1975) gathered data by building a model for discourse. As Seedhouse suggests, the IRF as a model for discourse will be used to analyze the discourse depicting the interactional patterns for this study.

Even though the IRF has been used to benchmark the findings of this study, there are some limitations to the foregoing discourse structure. One of them is that the analytical structure is so strict that it leads to lecturer domination (Saikko, 2007; Rajab, 2013). Supporting the foregoing limitations, (Križan, 2008; Waring, 2009) argued that the IRF was not the only pioneering and influential approach to the study of spoken discourse. Despite the said limitations, the IFR has been used in this study as it clearly shows the interactional patterns in ESL classrooms. This is because it was used to establish whether a "strict IRF" was followed or the different interactional patterns were shown.

\section{Research methodology}

\subsection{The Research Design}

To investigate the interactional patterns in ESL classrooms at Higher Learning, the study employed the qualitative approach. This approach was used in order to discover the trend(s) in regard to classroom talk in ESL contexts. A similar observation has been made by (Tafimow, 2014) who claimed that the two approaches are beneficial in learning more about goals and methods.

Even though the study used a qualitative approach only, it is worth noting that some literature offers contradictory findings on its use. Some of the research method scholars (e.g. Hammerberg., Kirkman \& de Lacey, 2016) argued that the results are often biased based on the researcher's own experiences. Despite the said observation, the study has used both the lesson transcripts and the classroom talk illustrations in order to address the challenge of biasness.

\subsection{The sample}

The study was conducted at the University of Botswana (UB). The population of the study was all first-year students in CSS classes and a sample of 365 students was used for this study. Seven lecturers were also sampled through convenience sampling. The participating lecturers were from all the seven faculties of the UB being; Humanities, Business, Engineering and Technology, Science, Social Science, Education, Health Science. The lecturers and their students were observed in order to get information on how the interactional patterns were shown during the teaching and learning process. All the participants in this study were given pseudonyms.

\subsection{Instruments}

To understand the interactional patterns at $U B$, the classroom observations were used as the research instruments for this study. The researcher and the research assistant would come early to class in order to prepare for the start of the lesson without any delays. Coming early to class also helped familiarize the research pair with the environment. The research assistant captured the classroom talk using a video camera to later evaluate the different interactional behaviors that emanated during the process. The classroom observations were used to show the qualitative results regarding the interactional patterns.

\subsection{Data Collection and analysis}

Using the classroom observations, data were collected from the seven lecturers and the group of students that each taught. The data, not shown in this paper, from the classroom observations, were analyzed by transcribing the video-recorded lessons using the IRF analytical tool (refer to appendices). Thereafter, the transcriptions were read through by the researcher, and the common themes were identified and grouped accordingly. Finally, the patterns of classroom talk were established by analyzing the length and depth of the classroom talk which revealed the qualitative results (Smart \& Marshall, 2013) from which the interactional illustrations were shown. 


\section{The Results and Discussion}

The findings of this study were analyzed and presented using the following comparative and superlative adjectives: "better"; "good" and "not so good". In this paper, "not so good" meant that in most cases, the teaching strands followed the strict IRF pattern and the strands were not more than three. Moving on to another data analysis category, there was the "good" pattern of interaction which indicated that the strands were not more than seven and the interactional pattern did not completely follow a strict IRF; and "better" meant that the strands were more than seven and the interactional pattern did not follow a strict IRF; there was evidence of longer teaching exchanges (more than two) which contributed to quality interaction.

\subsection{Lecturer Sarah \\ Lesson: Improving Note-taking \\ Faculty: Science}

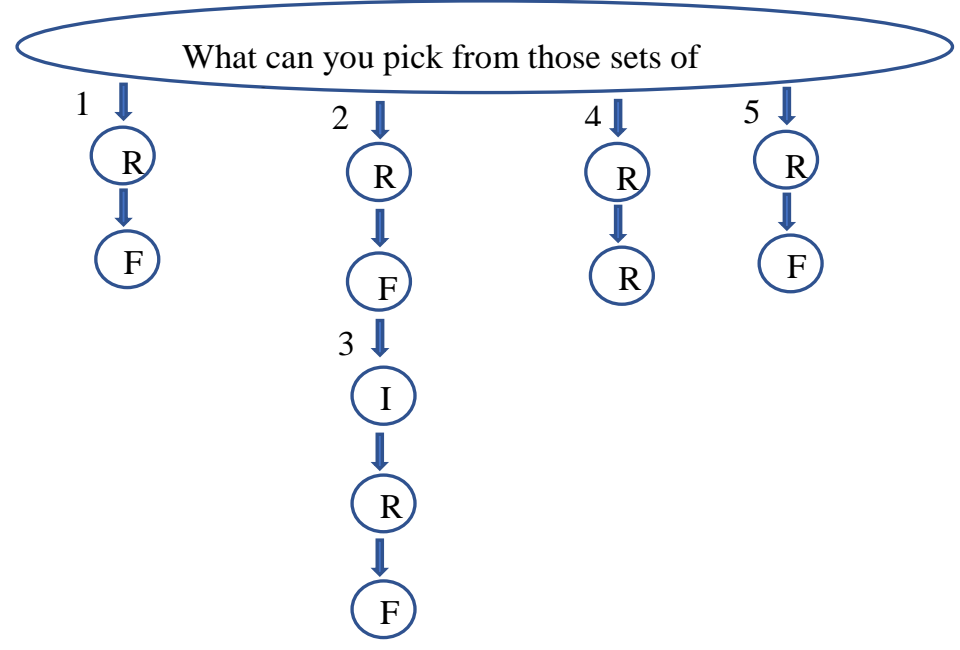

Figure 1

The above visual illustration indicates that lecturer Sarah, in her class, used an open question which read, "What can you pick from those set of notes?" It is an open question because there is a great possibility of students identifying a number of factors that relate to Note-taking.

Based on the data analysis category above, the analysis falls under the 'good' pattern of interaction. Teaching exchanges 2 and 3 developed detailed information about the types of notes that were used during the lesson. This is because lecturer Sarah probed the student's response by asking, "what else?" According to Galegane (2015), students have to think of correct and elaborative answers when they are probed for more information. In relation to the SCT, the aforementioned question acted as a scaffolding, coconstruction of knowledge, and mediation component. The question helped the students to come up with the question, based on the lecturer's assistance of probing. During the same question, there was also co-construction of knowledge because the lecturer and the students worked together in coming up with the answers to the question, "What can you pick from those set of notes?" The co-construction of knowledge relates to what scholars of dialogic classrooms term Collaborative patterns (Wanatabe \& Swain, 2007; Hakim, 2018; Sari, 2018) because they indicate a combined academic effort between the students and the lecturer. From another related angle, Mameli \& Molinari (2014) termed "Dialogic Interactive Orientations". This is where the students and the lecturer work together to develop classroom talk and think about the answers that they provide. It is also interesting to note that the above scholars' claim of thinking while providing answers, depicts the mediation component of the SCT. It can be claimed that teaching exchanges 2 and 3 demonstrated a 'good' pattern of interaction because students were probed for more responses which led to an interactive classroom.

Even though the above lesson illustration fell under the 'good' category, it is worth mentioning that there were three strands that showed the "strict IRF". In analyzing discourse patterns in multilingual classrooms, Amin \& Badreddine (2019), argued that the "strict IRF" is where the teachers controlled the topic under discussion. In the said three strands, the lecturer did not help the students to expand on the classroom interaction. After each of the students' responses, there was more lecturer talk because the lecturer prolonged the information to the students. The prolonged talk was observed at both the Initiation Move and the Feedback Move. With regard to more lecturer talk in ESL classrooms, Puasa, Asrifan \& Chen, (2017) argue that a large amount of teacher talking time limits the number of students talking time. Making reference to the SCT, it can be claimed that the key components of the theory 
were not applicable. For co-construction of knowledge, Lecturer Pretty seems to have not helped the students to control the class in terms of her and the students working together to bring forth dialogic interactional patterns based on the topic, "What can you pick from those set of notes?" A deficiency was also noted in terms of scaffolding and mediation because there was lack of development of the subject matter and critically thinking on the same.

\subsection{Lecturer: David}

Lesson topic: Academic Writing Style

Faculty: Business

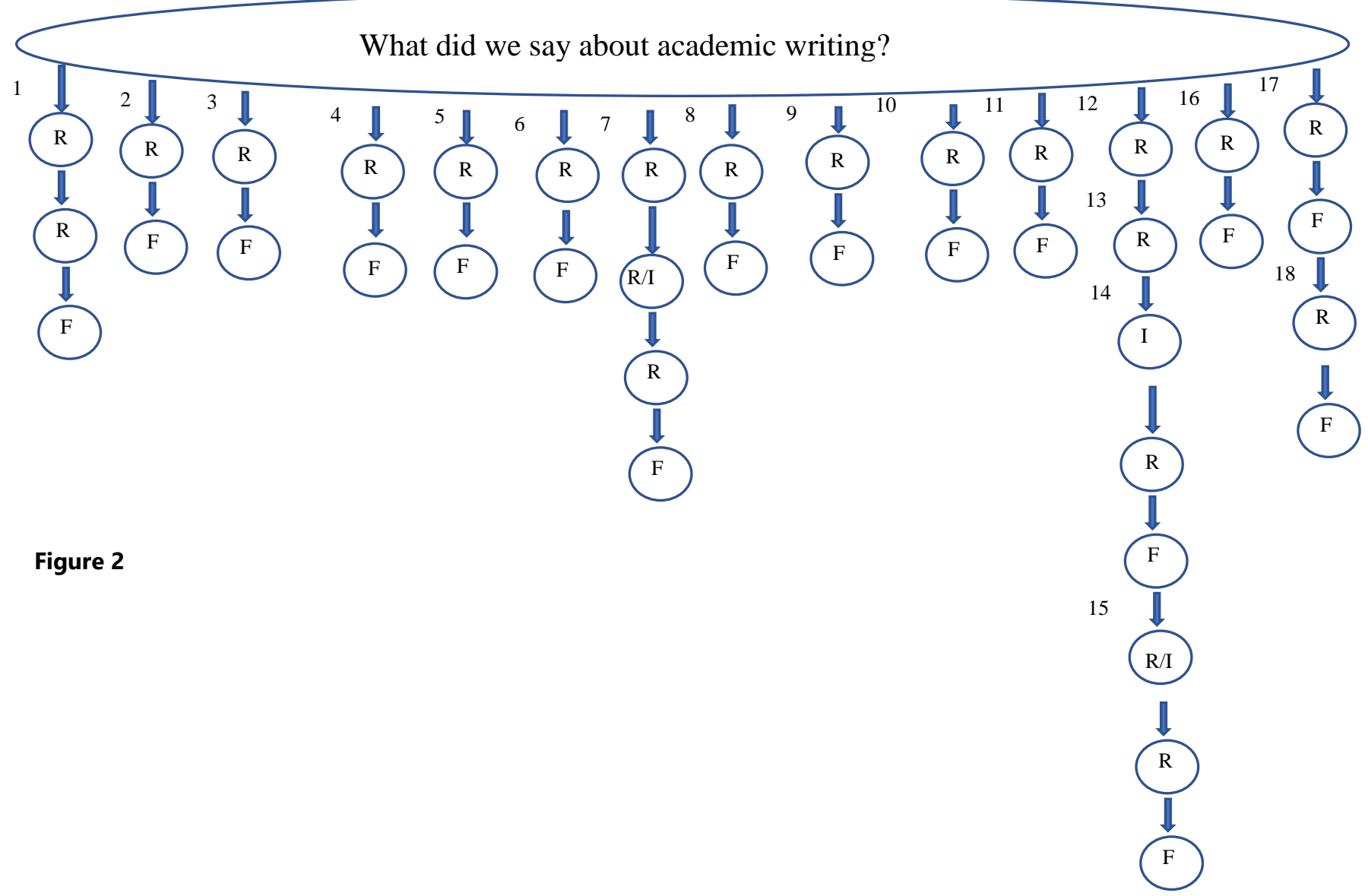

The above illustration demonstrates how the interactional patterns unfolded in lecturer David's class. The interactional analysis pattern from Lecturer David's class was "better" because there are numerous strands (more than seven) and there are longer teaching exchanges as indicated by $7,12-15$, and 17-18). The lesson started with the IRRF exchange which was followed by five strands indicating the "strict IRF". From the findings, there seem to be some other patterns of interaction, though minimal, besides the "strict IRF". For teaching exchanges 12-13, the IRR structure develops an extended classroom talk because the students "took the floor for a longer time". The findings suggest that there are some different interactional patterns (Seedhouse, 1996; Zakime 2019) in different contexts such as the UB. The said patterns could be a result of the teaching methods that the lecturers use. According to Daşkin (2015), the interactional patterns differ because the linguistic forms produced by the learners are not exactly identical to those intended by the teacher's pedagogical focus. Further, the patterns have variations because UB students are mature and are in a position to use critical thinking skills (Galegane, 2015; Phillips \& Bond, 2004). The aforementioned findings also relate to the SCT's co-construction of knowledge, scaffolding, and mediation component because a prolonged teaching exchange indicates that the lecturer posed open questions and the students critically thought of the answers they provided. 


\subsection{Lecturer: Deborah Lesson topic: Reading Skills \\ Faculty: Social Sciences}

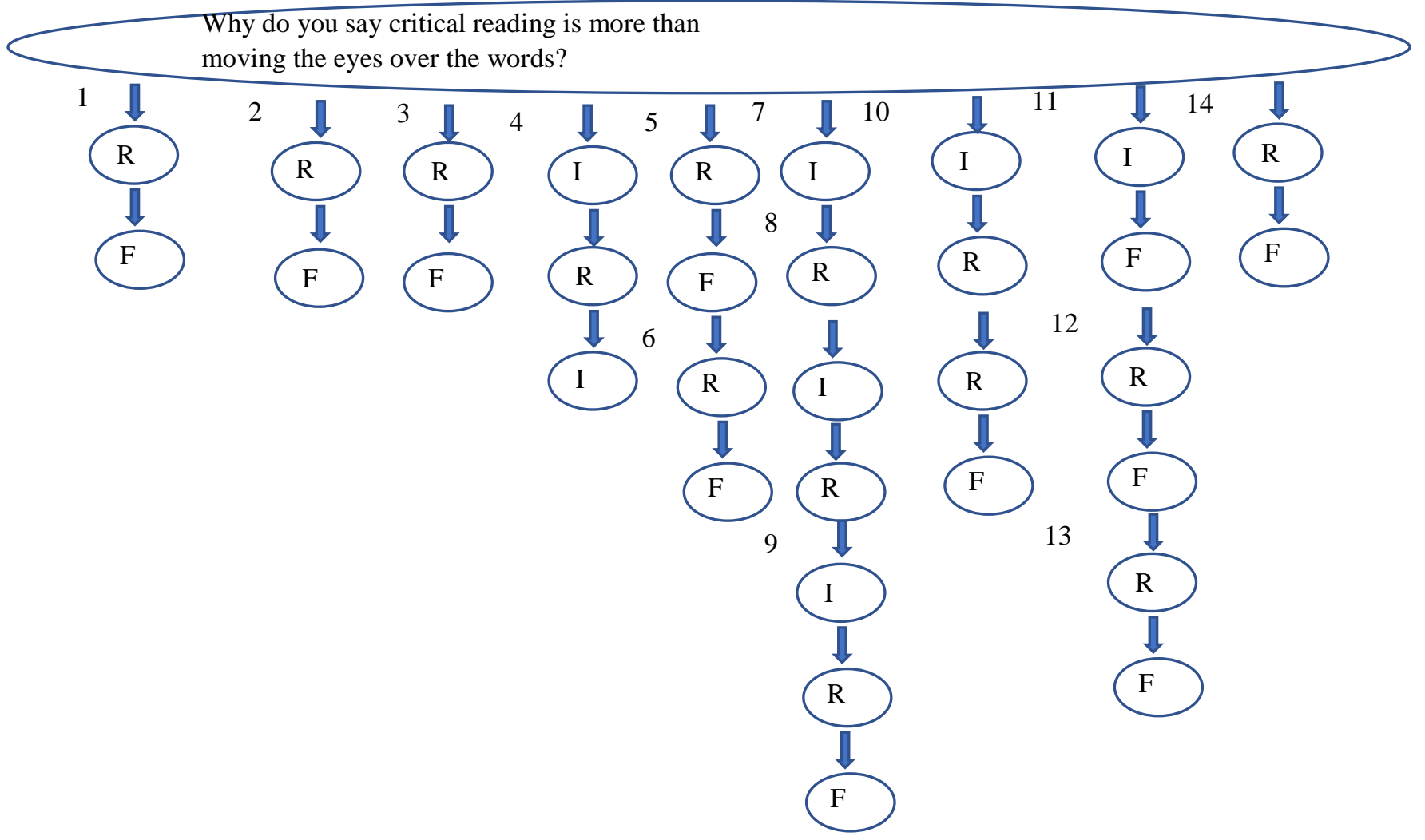

Figure 3

Figure 3 above depicts the interactional pattern used by Lecturer Deborah and her class. Four teaching exchanges (1, 2, 3, and 14), used a "strict IRF" which was observed by other classroom discourse analysts (e.g. Saikko, 2007; Rajab, 2013). The other five strands, teaching exchange 4-13 demonstrate varied interactional patterns such as IR, RF, and IRF. Such varied interactional patterns may reveal that the lecturers and the students are moving from the "strict IRF". This further indicates the positive development in university classrooms as regards the quality of classroom talk. This is because, as demonstrated by teaching exchanges 5-13, the aforementioned 'new' interactional structures led to prolonged discourse hence, "good" interactional patterns in the Social Sciences class which was taught CSS. Just like in Deborah's lesson, all the three tenets of the SCT, discussed above, were addressed because teaching exchanges 4-13 were elaborate and showed varied interactional patterns which depicted evidence of quality classroom talk.

\subsection{Lecturer: Mary}

Lesson topic: Reading and Writing

Faculty: Education

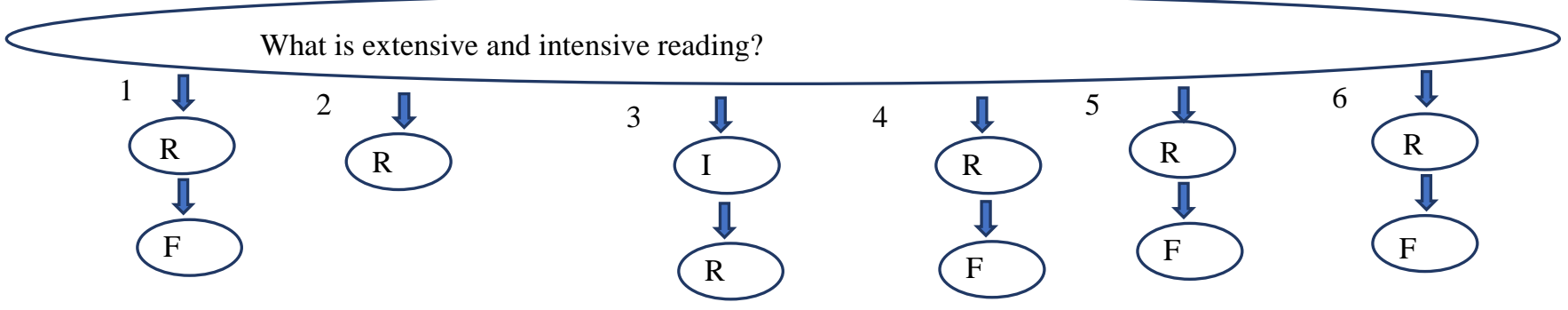

Figure 4 
For Figure 4, the interactional patterns predominantly revolved around the use of the "strict IRF" as observed by other scholars (e.g. Bunyi, 2005; Saikko, 2007; Rajab, 2015; Amin, \& Badreddine, D, 2019) except for teaching exchange 2 where the pattern was only the IR. Thus, the foregoing illustration reveals the 'not so good' interactional pattern. The above pattern also reflects that there was a lack of quality classroom talk in this class. It is interesting to note that, even though lecturer Mary had posed an open question, the interactional outcome did not open up for dialogic and quality talk. Thus, it can be concluded that lecturer Mary did not use a range of devices (Westgate., \& Hughes, 1997) to help break the use of the "strict IRF".

\subsection{Lecturer: Mary \\ Lesson topic: Listening and Note-taking \\ Faculty: Health Sciences}

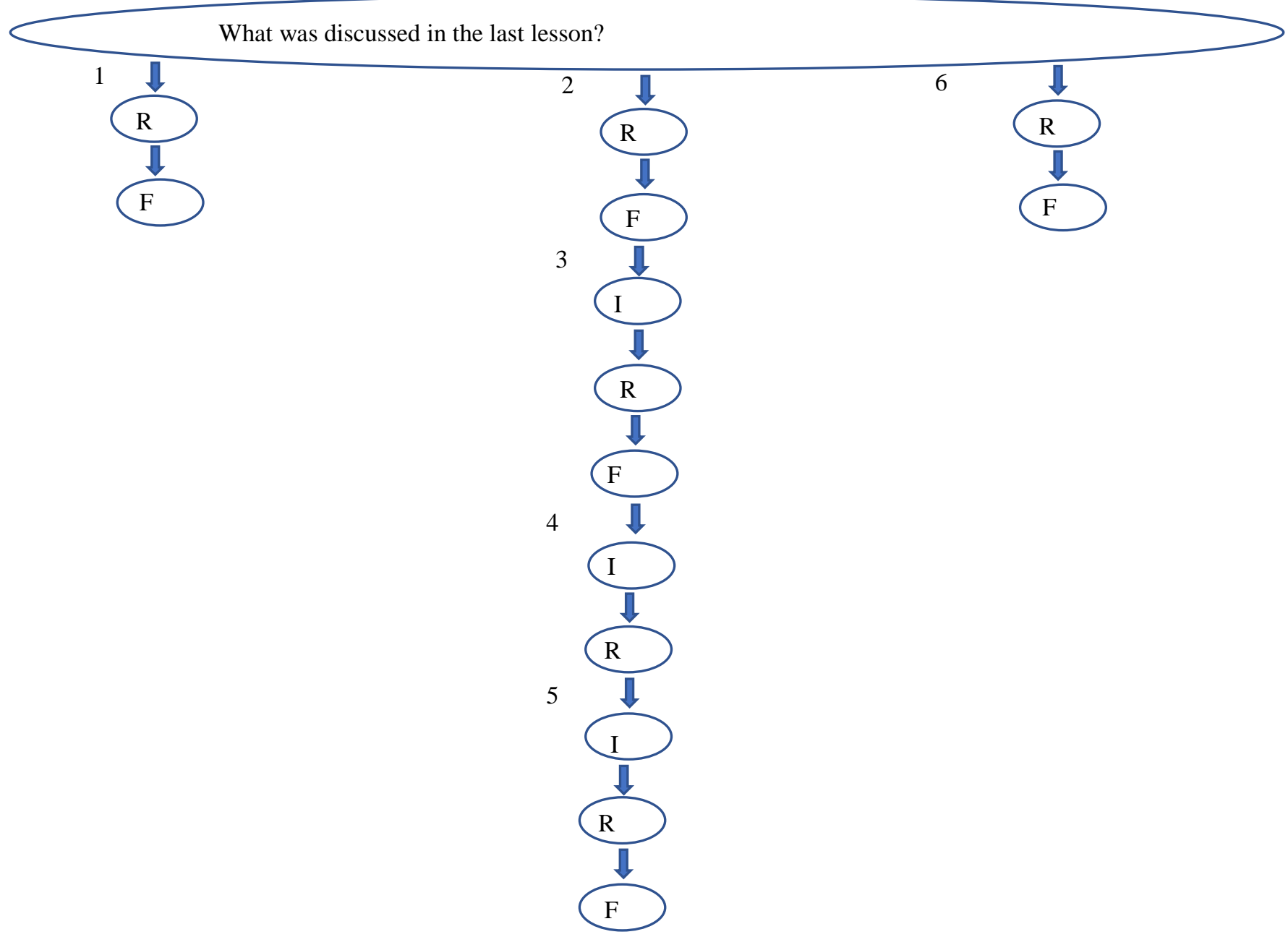

Figure 5

Based on Figure 5 above, the illustration reveals the "good" interactional analysis pattern. This was because the IRF was not strictly followed in Lecturer Mary's lesson. The "strict IRF" was found in teaching exchanges 1 and 6 while teaching exchanges $2-5$ showed an elaborate talk. The lesson started with an open question and the students came up with different points of view, more so that the question sort to solicit what was learned in the previous lesson. It can be argued that since the lesson was a revision, teaching exchanges 2-5 were prolonged. There was evidence of critical thinking during the said teaching exchanges leading to the "good" interactional patterns in Lecturer Mary's lesson. From a sociocultural point of view, it can be argued that the lecturer used the language from the previous lesson as the main tool that promoted the students' thinking (Vygotsky, 1978). 
4.6 Lecturer: Elizabeth

Lesson topic: Reading strategies

Faculty: Social Sciences

What is reading?

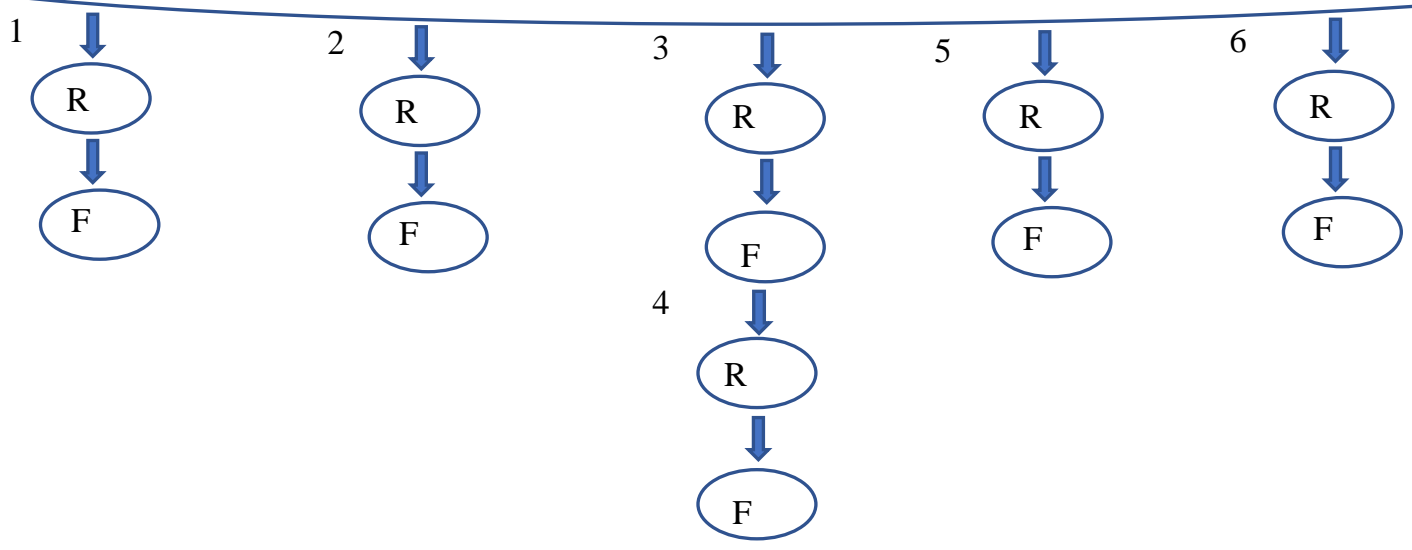

Figure

Lecturer Elizabeth's lesson in Figure 6 above indicated a "good" interactional pattern because the strands were not more than seven and the lesson did not follow a strict IRF. Although an open question was used during the lesson, which could have generated a prolonged dialogue, it is worth noting that instead most of the teaching exchanges (1, 2, 5, and 6), followed a "strict IRF" which according to (Kreece, 2009) shows lecturer dominance. It can also be argued that Lecturer Elizabeth missed opportunities (Khoza \& Nyamupangedengu, 2018) of probing students so that they can come up with more information on the question, "What is reading?"

\subsection{Lecturer: Magdaline}

Lesson topic: Why is listening important?

Faculty: Humanities

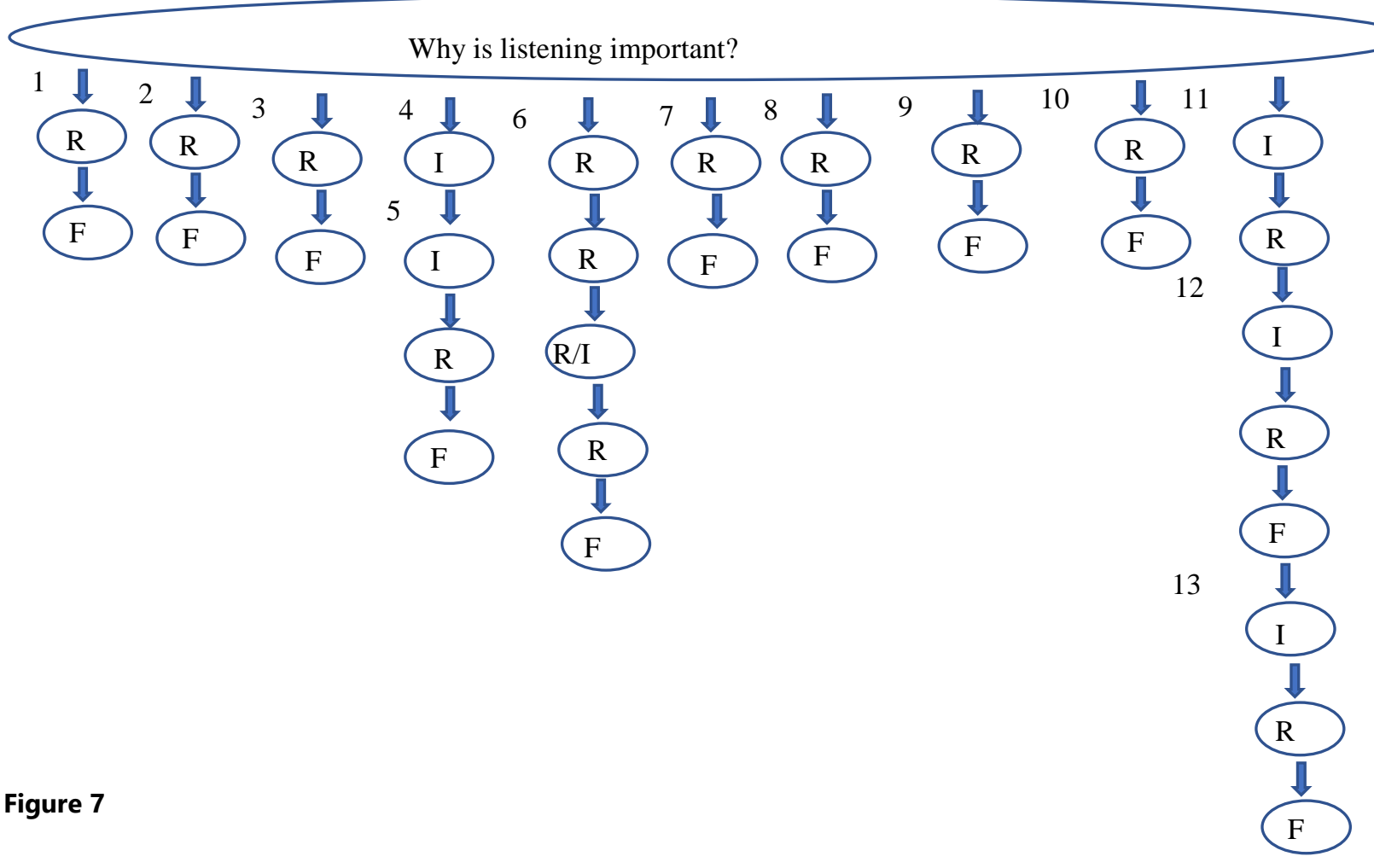


The above results shown in Figure 7 were for the Humanities students who were taught a lesson on "Listening". The lesson was categorized as "better" because the strands were more than seven and the interactional pattern did not follow a strict IRF. From the above figure, seven strands portrayed the 'strict IRF' (Bunyi, 2005; Saikko, 2007; Amin, \& Badreddine, D, 2019). On the other hand, three strands showed the interactional pattern where there was a prolonged talk and the IR and the IRR patterns were displayed. It is interesting to note that teaching exchanges 11-13 showed the longest talk for this class and the IRF was used in two teaching exchanges. These results are the same as Lecturer Sarah's longer interactional patterns. This is because, in both classes, the IRF was used to produce two to three teaching exchanges. Thus, it can be claimed that the IRF, in some cases, cannot be 'strict'.

\section{Implications of the study}

This study has implications for literature, practice, and further research. For the literature, this study will add more information to the literature on classroom interactional patterns by showing that there are other structures of interaction besides Sinclair \& Coulthard's IRF. There are IR, RF, IRR, IRRF patterns as indicated in the University of Botswana CSS classrooms. Regarding practice, this study provides information to practitioners at all levels of learning to always prolong their classroom interaction by probing for more questions towards the end of a teaching exchange. Finally, the study will contribute to further research as it will enable classroom discourse researchers to investigate the topic in other i) faculties of the University of Botswana ii) educational contexts of Botswana.

The results of this study further indicate three interactional patterns in the CSS classes of the University of Botswana. The three patterns would, in this study, be termed, "Better"; "Good" and "Not so good" (BGN patterns). Based on Seliger's (1977) categorization of interactional patterns, it can therefore be assumed that a relationship exists between a 'better' pattern and a high input generator. Further, a "Good" pattern was identified with the middle input generator while a "Not so good" pattern was identified with low input generators.

\section{Limitations of the study}

While describing and analyzing the interactional patterns which were reflected by the students and lecturers in Communication and Study Skills (CSS) classes of the University of Botswana, the use of only the qualitative research method was a limitation. However, carrying out further studies which involve mixed methods could help to analyze the findings on interactional patterns from a broader and more informed perspective. Also, a similar type of study could be carried out in other ESL contexts such as the primary, junior and secondary schools

\section{Conclusions}

The findings from the CSS classes at the University of Botswana, which is an ESL context, revealed that there was a positive shift regarding the interactional patterns which were categorized as "better", "good", and "not so good" (BGN interactional patterns). This is because most of the classes revealed the "better" as the highest, followed by "good" and finally, the "not so good" interactional patterns which were minimal. It can thus be concluded that the results of this study show that there is an attempt to produce quality classroom interaction which according to analysts of classroom talk (e.g. Alexander, 2008) teachers seek to shift from interactions that are brief and random (using the "strict IRF") to those which give the students an opportunity to provide longer and more sustained classroom talk, for example, using the Initiation, Response, Response (IRR) and the Initiation Response, Response, Feedback (IRRF).

\section{References}

[1] Alexander, R. (2008). Towards dialogic teaching: Rethinking classroom talk (4th Ed.), York: Dialogos.

[2] Aranda, M. L., Lie, R., Guzey, S. S., Makarsu, M., Johnston, A., \& Moore, T. J. (2020). Examining teacher talk in an engineering design-based science curricular unit. Research in Science Education, 50(2), 469-487.

[3] Amin, T., \& Badreddine, D. (2019). Teaching science in Arabic: diglossia and discourse patterns in the elementary classroom. International Journal of Science Education, DOI: 10.1080/09500693.2019.1629039.

[4] Brown, H. D. (2007). Teaching by principles: An interactive approach to language pedagogy. New York: Pearson Education.

[5] Bunyi, (2005). Language classroom practices in Kenya. In A.M.Y, Lin \& P.W, Martin (Eds) Decolonisation, Globalisation: Language-in-Education Policy and Practice. Clevedon: Multilingual Matters.

[6] Creese, A. (2006). Supporting talk? Partnership teachers in classroom interaction. International Journal of Bilingual Education and Bilingualism, 9(4), 434-453.

[7] Cross, J. (2010). Raising L2 listeners' metacognitive awareness: A sociocultural theory perspective, Language Awareness, $19(4), 281-297$.

[8] Daşkin, N. C. (2015). Shaping learner contributions in an EFL classroom: Implications for L2 classroom interactional competence. Classroom Discourse, 6 (1), 33 - 56.

[9] Galegane, G. (2015). A study of student-lecturer interaction in communication and study skills classes at the University of Botswana. Unpublished Ph.D. Thesis. The University of York.

[10] Goodwin, P. (Ed). (2012). The articulate classroom: Talking and learning in the primary classroom. London: Routledge. 
[11] Hakim, B. (2018). The impact of collaboration on the process-based writing in EFL classrooms in Saudi Arabia. International Journal of English Linguistics, 8(6), 164-171.

[12] Hammerberg, K., Kirkman, M., \& de Lacey, S. (2016). Qualitative Research Methods: When to use them and how to judge them. Human Reproduction, 31(3), 498-501.

[13] Hennessy, S., Warwick, P., \& Mercer, N. (2011). A dialogic inquiry approach to working with teachers in developing classroom dialogue. Teachers College Record, 113(9), 1906-1959.

[14] Inamullah, H. M., Naseer ud din, M., \& Hussain, I. (2008). Contemporary Issues in Education, 1 (1), 45-50.

[15] Khoza, H. C., \& Nyamupangedengu, E. (2018). Prompts Used by Biology Lecturers in Large Lecture Group Settings to Promote Student Interaction. African Journal of Research in Mathematics, Science and Technology Education, 22(3), 386-395.

[16] Križan, A. (2008). Classroom discourse: The applicability of Sinclair and Coulthard's IRF model. Retrieved on 12 February 2020 from https://stranijezici.ffzg.unizg.hr/wp-content/uploads/2018/09/sj40 2 str95-110.pdf.

[17] Lantolf, J. P. (2000). Introducing sociocultural theory. In J. P. Lantolf (Ed.), Sociocultural Theory and Second Language Learning. Oxford: Oxford University Press.

[18] Lefstein, A., \& Snell, J. (2014). Better than best practice: Developing teaching and learning through dialogue. London: Routledge.

[19] Li, J. (2018). Investigating the Initiation-Response-Feedback cycle from moves to discourse: A comparative study of Chinese and Australian English Language classrooms. Unpublished Ph.D. thesis: University of New South Wales, Sydney.

[20] Maftoon, P., \& Ziafar, M. (2013). Effective Factors in Interactions within Japanese EFL Classrooms. The Clearing House, 86, 74-79.

[21] Mameli, C., \& Molinari, L. (2014). Seeking educational quality in the unfolding of classroom discourse: a focus on microtransactions. Language and Education, 28(2), 103-119.

[22] Panova, l., \& Lyster, R. (2002). Patterns of corrective feedback and uptake in an adult ESL classroom. TESOL Quarterly, 36(4), 573-595.

[23] Phillips, V., \& Bond, C. (2004). Undergraduates' experiences of critical thinking. Higher Education Research and Development, 23(3), 227-294.

[24] Rajab, T. (2013). Developing whole-class interactive teaching: meeting the training needs of Syrian EFL secondary school teachers. Unpublished Ph.D. thesis, University of York.

[25] Reznitskaya, A. (2012). Dialogic Teaching: Rethinking Language Use During Literature Discussions. The Reading Teacher, $65(7), 446-456$.

[26] Rustandi, A. (2017). An analysis of IRF (Initiation-Response-Feedback) on classroom interaction in EFL speaking class. Journal of English Education, Literature and Culture, 2 (1), 239-250.

[27] Saikko, V. (2007). Different student strategies for interactional power in the IRF pattern in an EFL classroom. A-Pro Gradu Thesis Unpublished, University of Jysäskylä.

[28] Sari, F. M., (2018). Patterns of Teaching -Learning Interaction in the EFL classroom

[29] Seedhouse, P. (1996). Classroom Interaction: possibilities and Impossibilities. ELT Journal, 50(1), 16-24.

[30] Seliger, H. W. (1977). Does practice make perfect?: A study of interaction patterns and L2 competence. Language Learning: A Journal of Research in Language Studies, 27(2), 263-278.

[31] Smart, J. B., \& Marshall, J. C. (2013). Interactions between classroom discourse, teacher questioning and student cognitive engagement in middle school in Science. Science Teacher, 24, 249-267.

[32] Sundari, H., Rafli, Z. \& Ridwan, S. (2017). Interaction patterns in English as foreign language classroom at lower secondary schools. English Review: Journal of English Education, 6 (1), 99-108.

[33] Thoms, J. J. (2012). Classroom discourse in the foreign language classroom: A review of the literature. Foreign Annals, 45(51), 58-527.

[34] Trafimow, D. (2014). Considering quantitative and qualitative issues together. Qualitative Research in Psychology, 11(1), 15-24.

[35] Turuk, M. C. (2008). The relevance and implications of Vygotsky's sociocultural theory in the second language classroom. ARECLS, 5, 244262.

[36] Wanatabe, Y., \& Swain, M. (2007). Effects of proficiency differences and patterns of pair interaction on second language learning: a collaborative dialogue between adult ESL learners. Language Teaching Research, 11(2), 121-142.

[37] Waring, H. Z. (2009). Moving out of the IRF (Initiation-Response-Feedback): A single case analysis. Language Learning: A Journal of Research in Language Learning.

[38] Wells, G. (1993). Reevaluating the IRF Sequence: A Proposal for the Articulation of Theories of Activity and Discourse for the Analysis of Teaching and Learning in the Classroom. Linguistics and Education 5, 1-37.

[39] Westgate, D., \& Hughes, M. (1997). Identifying 'quality' in classroom talk: enduring research task. Language and Education, 11(2), 125-139.

[40] Zakime, (2019). What are Patterns of Interaction?

[41] Zhan, Z., Wu, Q., Lin, Z., \& Cai, J. (2021). Smart classroom environments affect teacher-student interaction: Evidence from behavioral sequence analysis. Australasian Journal of Educational Technology, 37(2), 96-109. 